\title{
DESESPERO E SOFRIMENTO NO DISCURSO DE PESSOAS QUE PENSAM EM TIRAR A PRÓPRIA VIDA: UMA ANÁLISE EXISTENCIAL
}

\section{DESPAIR AND SUFFERING IN THE DISCOURSE OF PEOPLE WHO THINK ABOUT ENDING THEIR OWN LIVES: AN EXISTENTIAL ANALYSIS}

\author{
Ana Maria Lopez Calvo de Feijoo ${ }^{1}$ \\ Myriam Moreira Protasio ${ }^{2}$ \\ Guilherme da Silva Sant'Anna ${ }^{3}$
}

\begin{abstract}
Resumo: Esta investigação quer mostrar de que forma expressões de desespero e sofrimento estão presentes no discurso clínico de pessoas que se encontram entre o morrer e o viver. O interesse por estas expressões apareceu de forma relevante em uma primeira pesquisa sobre suicídio. Para alcançarmos a experiência dos analisandos, buscamos as expressões que caracterizavam o sofrer e o desesperar em sete atendimentos realizados no Núcleo de Atendimento Clínico a Pessoas em Risco de Suicídio do SPA da UERJ no segundo semestre de 2017. Procedemos à análise dessas situações clínicas, de modo a podermos descrever como o desespero e o sofrimento apareciam nos discursos dos analisandos. Concluímos não haver uma relação necessária entre sofrimento, desespero e indecisão acerca do suicídio.
\end{abstract}

Palavras-chave: Suicídio; Desespero; Sofrimento; Análise existencial; Hermenêutica.

\begin{abstract}
This research wants to show how expressions of despair and suffering are present in the clinical discourse of people who are between dying and living. The interest in these expressions appeared prominently in a first suicide survey. To achieve the experience, we seek for the expressions that characterized the suffering and the despair in seven attendances in the Nucleus of Clinical Care for People at Risk of Suicide at the SPA of UERJ in the second semester of 2017. The analysis of these clinical situations was carried out in order to describe how despair and suffering appeared in the discourses of the analysands. We conclude that there is no necessary relationship between suffering, despair and indecision on suicide.
\end{abstract}

Keywords: Suicide; Despair; Suffering; Existential analysis; Hermeneutics.

\section{Introdução}

Este trabalho é parte de uma pesquisa que começou em 2015, intitulada Por Um Núcleo de Atendimento Clínico a Pessoas em Risco de Suicídio: Uma Análise Fenomenológica do Ato de Decidir Pôr Fim à Vida (FEIJOO, 2016). A primeira parte dessa investigação desenvolveu-se no tocante aos seguintes aspectos: considerações

\footnotetext{
${ }^{1} \mathrm{PhD}$, Universidade Federal do Rio de Janeiro (UFRJ). Professora da Universidade do Estado do Rio de Janeiro (UERJ), Rio de Janeiro, RJ, Brasil. E-mail: ana.maria.feijoo@ gmail.com

${ }^{2} \mathrm{PhD}$, Universidade do Estado do Rio de Janeiro (UERJ). Universidade do Estado do Rio de Janeiro (UERJ), Rio de Janeiro, RJ, Brasil. myriam@ifen.com.br

${ }^{3}$ Graduando em Psicologia, Universidade do Estado do Rio de Janeiro (UERJ). Universidade do Estado do Rio de Janeiro (UERJ), Rio de Janeiro, RJ, Brasil. guilherme1995rj@gmail.com
} 
preliminares sobre a compreensão da finitude humana; suicídio: uma revisão sistemática da literatura; uma análise crítica dos estudos fenomenológicos sobre suicídio; um estudo sobre a moralização do suicídio; psicologia, suicídio e culpabilização; dor, sofrimento e pôr fim à vida: uma análise crítica; prevenção do suicídio, técnica e psicologia fenomenológico-existencial; estudos atuais sobre o suicídio infanto-juvenil; Camus e Kierkegaard: do absurdo ao desespero; a (in)decisão de pôr fim à vida: uma análise fenomenológica dos discursos clínicos; a poiésis do suicídio ou sobre a vida da morte possível; o sol poente: suicídio, memória e saudade na obra de Carlos Casares. Estes estudos foram publicados em um livro, organizado pela coordenadora da pesquisa, Professora Ana Maria Lopez Calvo de Feijoo (2018), intitulado Suicídio entre o morrer e o viver: desmoralizando o suicídio na contemporaneidade. O objetivo desta primeira etapa da pesquisa foi promover estudos acerca do suicídio na perspectiva fenomenológico-existencial, de modo a preparar os estudantes que prestavam atendimento clínico a pessoas que pensavam em tirar a própria vida e que procuravam ou eram encaminhadas por outros setores ao Serviço de Psicologia Aplicada (SPA) da Universidade do Estado do Rio de Janeiro (UERJ).

Essa primeira etapa da pesquisa deixou claro que era possível e necessário um centro de atendimento a pessoas que pensam em pôr fim à vida, bem como que os profissionais de psicologia precisavam de um preparo para tal demanda. Assim, pudemos cumprir dois dos objetivos da pesquisa: o primeiro, que visava atender à reivindicação feita em 2015 pela Organização Mundial da Saúde (OMS), citada por Feijoo (2016) - de que fossem criados mais núcleos de atendimento a pessoas que têm ideias suicidas. Nessa oportunidade criamos o Núcleo de Atendimento Clínico a Pessoas em Risco de Suicídio (NAC). O segundo objetivo consistia em atender à solicitação do Conselho Regional de Psicologia de São Paulo - para que houvesse um maior investimento no preparo dos profissionais de psicologia para a atuação clínica com pessoas que pensam em pôr fim à vida (SANTOS, 2011). Assim, finalizamos a primeira parte da pesquisa criando o NAC com profissionais e estudantes habilitados ao exercício clínico com pessoas que pensavam em suicídio. A preparação dos estudantes e dos profissionais voluntários aconteceu por meio de estudos sobre o tema e pelos próprios atendimentos clínicos. Esses atendimentos eram levados para a supervisão, quando procedíamos à análise existencial na situação dos quatro analisandos que se encontravam em atendimento, conforme relatado em Xavier (2018). Essa autora explicitou que nas falas das pessoas que pensavam em suicídio muitos sentidos se articulavam, tais como: auto-identidade; 
autodesvalorização; relações de densidade existencial; pedido de ajuda; ambiguidade; sentimento de não aceitação social; dificuldade de lida com adversidades; evitação do sofrimento; inutilidade; insatisfação com terapias anteriores; estranhamento em relação aos sentimentos.

Dois temas específicos se faziam muito presentes nesses atendimentos clínicos: sofrimento e desespero. Resolvemos, então, demorar-nos naquilo que estava presente quando as pessoas se referiam ao desespero e ao sofrimento. A expressão de sofrimento e de desespero vem marcada pelo horizonte histórico de constituição de sentidos e de significados, daí estarem presentes nas falas dos analisandos. Surgiram, pois, algumas questões: São o sofrimento e o desespero características intrínsecas daquele que pensa em suicídio? O que estes analisandos queriam dizer quando se expressavam por meio das palavras sofrimento e desespero? Movidos por essas questões, resolvemos nos dirigir aos discursos de alguns analisandos que foram atendidos no NAC no segundo semestre de 2017 de forma a realizar uma análise existencial das situações trazidas pelos mesmos. A análise existencial será, portanto, o método de análise deste trabalho.

Começamos por investigar o que os pensadores da perspectiva existencial tinham a nos dizer sobre estes temas, o que desenvolveremos na primeira sessão deste trabalho. Compreendendo o trazido por esses pensadores, pudemos sair de uma postura ingênua sobre o tema e avançar com maior entendimento a respeito de desespero e sofrimento. Com a ajuda destes pensadores, pudemos realizar a suspensão do que habitualmente se entende por desespero e sofrimento, de forma a nos dirigirmos mais livremente aos discursos dos analisandos. Antes de tomarmos os discursos propriamente ditos, apresentaremos a metodologia que adotamos para nossa investigação. Procedemos a análise das descrições dos relatos concernentes ao modo de existir ou de estar ao mundo de sete sujeitos em situação de atendimento clínico, tomados como significativos por apresentarem indícios de sofrimento e desespero e, veladamente, apontarem para possível suicídio. Os atendimentos foram realizados por seis estudantes-terapeutas no segundo semestre de 2017. Nossa análise levará sempre em consideração o modo de lida de cada analisando com o desespero e o sofrimento, tentando descrever o modo como cada analisando se articula com sua própria realidade. 


\section{Desespero e sofrimento: considerações filosóficas}

Em nossos estudos ficou evidente a compreensão vigente de que há uma correlação direta entre sofrimento, desespero e tentativas de suicídio. $\mathrm{O}$ desespero se mostrou, à luz do pensador Sören Kierkegaard (2010b), como a própria condição do homem que não pode colocar a si mesmo e precisa constituir-se nas condições que lhe são abertas na existência, pois o homem existe sempre na duplicidade entre as condições em que existe e a tarefa de ter de constituir-se como este que ele pode ser, e essa é sua dor. Neste sentido, estar desesperado é, de algum modo, querer impor à própria vida os modos de sua existência se dar, num esforço por transformar o que não é possível modificar, ou recusar-se a existir assumindo as condições de sua realidade.

No que concerne ao sofrimento, Kierkegaard (1992) e Fogel (2010) consideram que o mesmo é possibilitado pela experiência originária da dor, ou seja, tem a dor como seu fundamento. Dor, nessa acepção, corresponde ao constante caráter trágico da existência e a uma condição constituinte do próprio ser humano, portanto, inevitável. Sofrimento, por seu lado, consiste na experiência de se enfadar com a dor da vida, a dor porque se tem dor. Metaforicamente, podemos ilustrar essas noções ao compararmos a dor a uma ferida ardendo e o sofrimento à lamentação por estar ferido e ardendo.

Vamos nos demorar um pouco mais nas considerações filosóficas acerca do desespero e sofrimento.

\subsection{Desespero}

O desespero é compreendido, habitualmente, como um sentimento negativo, ameaçador, que deve ser extirpado, mostrando-se nos discursos por meio do ressentimento ou da lamentação em relação às condições dadas na existência. Estas mesmas condições servem como justificativas para uma certa inação ou paralisia existencial. A crença mais comum é que a alteração das circunstâncias externas faria desaparecer o desespero.

De acordo com Kierkegaard (2010b), desespero é a própria condição existencial, pois o homem não pode posicionar a si mesmo, não pode determinar as condições de sua existência, e precisa constituir a si mesmo nestas condições. Assim, Anticlimacus (KIERKEGAARD, 2010b) defende que o eu é desespero, pois existe sempre em duplicidade, em tensão com as condições dadas, e é nessa duplicidade que ele tem de ser, 
ou seja, tem de existir. Estar desesperado ou desesperançado é já uma modulação dessa condição mais originária. Kierkegaard (2010b) vai mostrar que o homem se constitui numa tensão paradoxal entre contingência (finitude) e imaginação (infinitude); entre as condições dadas que o limitam (os necessários, nos quais não é livre) e a possibilidade de transcender esses limites (liberdade); entre a consciência de si mesmo como temporal e a experiência de elasticidade e de lastro existencial que lhe acena para a duração ou eterno de sua existência. Por isso, o homem existe como uma conjunção disjuntiva que une o que parece desunido e alcança sentidos que a razão interdita. Esse elemento é importante, pois o que está em questão na compreensão do desespero é que o homem quer impor a medida de sua existência, quer estabelecer as condições. Mas, sustenta Anticlimacus, neste querer ele pode encontrar a sua própria medida, saltando para uma existência livre de ilusões.

Sim, porque, como nos aponta Kierkegaard (FERRO, 2015; PROTASIO, 2018), o homem gosta de ilusões e tem preferência pelo engano. Ele tende a articular-se de forma a esquecer-se de sua condição paradoxal e mergulhar na tentativa de encontrar um caminho unívoco e uma saída rápida para a tensão. O homem gosta de acreditar que sua vontade é soberana e que pode, por sua própria vontade, transformar suas condições. Ora, claro que há muito que o homem pode fazer, e faz. Isso não implica conseguir tudo o que quer, ou mesmo ter as condições na medida de seu desejo. Segundo Feijoo (2016), essa é a doença do homem moderno, que quer, a qualquer preço, impor as condições e acredita que querer é poder.

Anticlimacus (KIERKEGAARD, 2010b) nos traz que desespero tem a ver com a consciência de saber-se de si. Ou seja, o homem constitui-se como desespero porque já sabe de sua condição de lançado na existência e dos riscos desta sua situação. Por isso ele desespera, ou seja, teme, antecipa, ressente-se, torna-se melancólico, culpa o outro, culpa a si mesmo por não ter feito o que deveria, frustra-se por ter que encarar a realidade de suas condições, fecha-se em si mesmo, pensa em tirar a própria vida, etc. O homem sabe que tem um papel em seu próprio destino. A questão, então, está nos modos como o homem se articula com a sua condição de desespero, ou seja, no modo como ele se articula com as condições (contingentes) de sua existência e em tensão com a possibilidade (o transcendente).

Como tentamos mostrar, o eu é desespero porque existir é sempre esse campo no qual as condições se desenham e as possibilidades se abrem. Mas estar desesperado é outra coisa, significa ser presa da ilusão de poder o que não pode ou de não poder o que 
pode. Significa não aceitar a existência em suas imposições e possibilidades, tentando instituir sua própria vontade contra as condições dadas, ou seja, que as ações estão desafinadas em relação às condições dadas e em relação ao horizonte que as sustenta (PROTASIO, 2018). Num horizonte em que querer é poder, estar desesperado se mostra quase como a ordem do dia e o homem quer, por força, fazer com que se cumpra a sua vontade. Mas, segundo o que estamos desenvolvendo, estar desesperado é o contrário de transparecer para si mesmo em sua condição de desespero, ou seja, de se constituir a partir desta duplicidade que sustenta tanto a finitude, a temporalidade e o necessário quanto o infinito, o eterno e a liberdade. Anticlimacus (KIERKEGAARD, 2010b) acredita que um homem pode entender a diferença entre estar desesperado e constituir-se como desespero. E que, ao entendê-la, ele pode conquistar a si mesmo como conjunção disjuntiva de elementos em constante tensão, abdicando de toda ilusão e de toda desesperança.

\subsection{Sofrimento}

Em nosso cotidiano, os termos dor e sofrimento costumam ser usados para designar experiências de ordem biológica ou psicológica. Além disso, há uma tendência ao uso de tais palavras como sinônimos e a assunção de sua similaridade com as experiências de aflição, amargura, padecimento físico, dissabor, pesar, etc. Apresentamos, no livro Suicídio entre o morrer e o viver: desmoralizando o suicídio na contemporaneidade, a diferenciação de dor e sofrimento em uma perspectiva existencial (SANT'ANNA, 2018). Consideramos que o obscurecimento dessa diferença propicia o posicionamento do sofrimento como imprescindível ao suicídio, pouco contribuindo para a compreensão das experiências dos indecisos em findar suas vidas. Aqui, retomamos essa distinção com a intenção de darmos um passo adiante: após as considerações filosóficas, analisarmos os discursos clínicos a fim de evidenciarmos como as experiências de dor e sofrimento aparecem nos mesmos.

O pensador dinamarquês Sören Kierkegaard, além de escrever sobre o desespero, redigiu sobre o sofrimento. Ele tenta, em Ancient's Tragedy Reflection In The Modern, expor traços que diferenciam duas modalidades de tragédia: a antiga e a moderna (KIERKEGAARD, 1992). Um de seus argumentos é o de que a diferença entre os dois tipos se manifesta na culpa do herói trágico, na atribuição da responsabilidade pelo arranjo da tragédia. Desse modo, o autor nos propõe interessante reflexão sobre o tema da dor e do sofrimento nos antigos e nos modernos. 
Como podemos ver em Sant'Anna (2018), a culpa na tragédia antiga tem como elementos integrantes a família, o destino e a ação do herói. Não se concebe o herói como apartado dos outros e como único responsável por suas ações, posto que seu parentesco, sua história e sua sorte contribuem para a tragédia. A ação e a culpa são, portanto, intermediárias entre o atuar e o padecer, estando o interesse trágico situado nesse meio. O trágico se encontra, então, entre os extremos da ausência de culpa e da culpa absoluta. Na modernidade, há uma preponderância desta última extremidade, tende-se a considerar o indivíduo como único responsável pela tragédia. Assim, reduz-se equivocadamente o caráter trágico da existência às ações individuais, prevalecendo uma compreensão subjetiva sobre a existência na tragédia moderna (KIERKEGAARD, 1992).

Há uma distinção na ênfase da dor e do sofrimento em cada tipo de tragédia, em razão da diferenciação na culpa do herói trágico. Na tragédia moderna, Kierkegaard (1992) assevera que pain (sofrimento) é maior que sorrow (dor), isto é, a reflexão sobre a dor é maior que a própria dor. Na antiga ocorre o contrário, ou seja, a dor é mais profunda que o sofrimento. O pensador aponta não só para algo estrutural e próprio da vida, como também para uma possibilidade a partir dessa estrutura. Aqui, chamamos de dor essa condição própria da existência, o constante caráter trágico. O sofrimento, por seu turno, consiste na experiência de se zangar com a dor, de refletir sobre a dor.

Relembremos a metáfora já exposta neste trabalho, segundo a qual dor corresponde a uma ferida ardendo e o sofrimento à reclamação por estar ferido e ardendo. Viver é estar exposto à possibilidade de ter feridas, o que os gregos antigos já sabiam. Kierkegaard relata a tragédia vivida por Antígona, uma das filhas do rei Édipo. Este é um personagem célebre, visto que a trilogia contada por Sófocles é conhecida por muitos na qual um homem mata seu pai, desposa a própria mãe e depois toma ciência do anúncio de tais acontecimentos em uma antiga profecia. Seus dois filhos homens brigaram pelo trono após a sua renúncia, o que resultou na morte de ambos. Com isso, o tio deles assume o poder, autorizando o enterro daquele que foi seu aliado e proibindo, ao que foi considerado traidor, a prestação das honras funerárias. Quem tratasse de sepultar o cadáver, contra a ordem expressa, seria penalizado com a morte. Nesse contexto, estava a dor de Antígona, a herdeira de uma estirpe marcada de tragédias e que tinha, por um lado, a ordem do rei de não enterrar o morto e, por outro, o senso moral de honrar seu irmão. Ela decide pela segunda opção, ainda que fosse a sua morte o preço a pagar por essa decisão. Antígona se mata antes mesmo de sua condenação, desencadeando uma série de outros acontecimentos trágicos. Importa-nos ressaltar que, embora a história de 
Antígona seja claramente trágica, não aparece em seus relatos a lamentação por conta das circunstâncias. Sem dúvida, ela sente a ferida ardendo, mas não reclama por isso. A reflexão sobre a dor e a queixa relativa a fatos ocorridos não estavam presentes nos gregos antigos (KIERKEGAARD, 1992).

Para Fogel (2010), outro pensador da temática aqui abordada, dor é uma condição existencial e, portanto, inescapável. A dor, nesse sentido, é a dor do viver e de ter de ser. Esse significado difere do sentido usual de dor, como um padecimento físico ou algo de ordem sensorial. A dor, para esse filósofo, constitui e condiciona o ser humano, sendo componente da tarefa de termos que constituir a nós mesmos. Expressa, pois, a condição humana propriamente dita. Não convém, então, buscarmos extinguir essa dor, pois ela nos funda. Menos ainda, se consideramos que essa característica, o fato de termos de nos fazer a cada vez, distingue-nos dos demais entes. Para Fogel, um traço característico da modernidade é o sofrimento, o enfadar-se com a dor, sustentado pela crença na possibilidade de viver sem dor nenhuma, pela vontade de ter feito as coisas diferentemente e pelo reconhecimento da responsabilidade dos acontecimentos caberem exclusivamente ao indivíduo. Em vista disso, o sofrer se torna uma possibilidade com a não aceitação da dor própria da vida. Lamentando-nos pelo que poderia ter sido, ou queixando-nos com relação às condições de nossas existências, terminamos por nos afastar da experiência da dor que é a vida, experienciando, assim, o sofrimento (SANT'ANNA, 2018).

A possibilidade de o desespero ou o sofrimento motivarem o ato de pôr fim à própria vida não nos surpreende, visto que esta é uma crença comumente difundida em nossa sociedade. No entanto, se consideramos o sofrimento uma possibilidade a partir da experiência originária da dor, e o desespero como a própria condição daquele que pensa sobre sua existência, não devemos tomá-los como simples causa do pensar em suicídio, tampouco inferir sua presença naqueles que efetivam o suicídio. Como desespero e sofrimento aparecem no discurso de pessoas que pensam em tirar a própria vida? É para responder a essa pergunta que construímos essa investigação.

\section{Método}

A pergunta que nos guia nesta investigação diz respeito ao modo como aparece, no discurso dos analisandos, a lida com o desespero e o sofrimento. Para respondê-la, vamos nos debruçar sobre sete registros de atendimentos clínicos realizados no NAC, 
localizado no SPA da UERJ. Tais atendimentos envolveram 6 estudantes-terapeutas em atendimentos que aconteceram no segundo semestre de 2017. Tomaremos estes atendimentos no exposto em registros das discussões que tiveram lugar no ambiente de supervisão. Não criamos um protocolo de registros, tendo em vista uma situação específica de investigação, mas olhamos para o mundo-vida como experienciado em situações de supervisão clínica.

A supervisão efetiva uma parte central da pesquisa, pois cumpre pelo menos duas funções: orienta os alunos quanto aos atendimentos, o que já se constitui num exercício fenomenológico-hermenêutico, uma vez que não partimos de compreensões prévias, mas nos limitamos a ouvir o relato e captar a atmosfera denunciada pela situação de forma a alcançar os sentidos apontados pelo discurso; mas também serve para mantermos registrados os dados da experiência para serem usados em análises posteriores. O que estamos denominando de exercício fenomenológico-hermenêutico sustenta-se em dois pilares: a redução fenomenológica ou psicológica, com o objetivo de suspender, a cada instante, os posicionamentos ontológico-naturais; e a compreensão hermenêutica dos sentidos vigentes em um tempo, de modo a não sermos absorvidos irrefletidamente por interpretações já vigentes. Aqui estamos nos referindo a um momento da redução, que entendemos ser aquele de já colocar em destaque o fenômeno investigado e olhá-lo sem concepções a priori.

Para procedermos aos nossos estudos e investigarmos os sentidos que estão em jogo na indecisão de pôr fim à vida, estabelecemos a nossa rotina de trabalho por meio de uma análise do relato das experiências daquele que considera pôr fim à vida e vai a busca de atendimento clínico. A análise existencial sustenta-se no acompanhamento atento ao discurso, de modo a apreender a rede de significados em que o fenômeno se enreda. Do olhar atento para o fenômeno, no campo mesmo em que ele se dá a ver, colocando entre parênteses concepções prévias, é que se faz possível a compreensão do sentido que o vivido pelo sujeito em situação de atendimento clínico se evidencia em suas falas. O investigador, então, descreve o fenômeno do modo como ele se dá a ver em seu estar com o sujeito m situação de atendimento.

Ao nos debruçarmos exaustivamente sobre o tema, como dito no início deste artigo, estudando autores sem tomar sua obra como teoria a ser seguida, mas apenas como textos com os quais poderíamos dialogar sobre o tema por nós investigado, lendo textos mitológicos, de literatura e artigos sobre o suicídio em várias perspectivas, inclusive na perspectiva fenomenológico-existencial, nossa compreensão do fenômeno ampliou seu 
horizonte. Esse esforço de leitura, juntamente com aquele de não tomar os textos como uma teoria prévia a respeito do questionamento suicídio e atentos ao que os atendimento clínicos nos diziam, viabilizou o exercício da suspensão. Ficamos atentos para não tomar o discurso daqueles que pensam em tirar a própria vida de modo naturalístico, nem considerá-lo a partir de posicionamentos prévios sobre o que se diz acerca do que o fenômeno.

Compreendendo hermeneuticamente que os sentidos das experiências sempre se desdobram na temporalidade vivida, nossa pesquisa dirigiu-se para a tarefa de acompanhar, nos relatos registrados dos atendimentos realizados no segundo semestre de 2017, o modo como cada analisando se articula com a vida e, nesse seu modo de articular, o modo como aparecia a lida com o sofrimento e com o desespero. A isso denominamos análise existencial. Em uma análise existencial tomamos o homem como abertura dinâmica (FEIJOO; PROTASIO, 2011), sempre considerando seu caráter de indeterminação. Assim, o agir do homem não ocorre por necessidade, mas por possibilidade. É em liberdade que o homem age como age, pensa como pensa.

As temáticas do sofrimento e do desespero se mostraram relevantes nos discursos dos analisandos investigados na primeira parte da pesquisa, motivando esta nossa investigação. A análise existencial que temos em causa diz respeito aos modos de se articular com a existência em um determinado tempo, ou seja, sentidos existenciais que são imprimidos na lida cotidiana em uma época, a nossa. Dessa forma, a pesquisa que empreendemos se constitui mais como um caminho de pensamento do que propriamente uma metodologia em seu sentido tradicional (MAGLIANO, 2018). Trata-se de um demorar-se junto ao fenômeno, sem expectativas de encontrar uma verdade objetiva ou efetiva e, por isso, colocando em questão "nosso próprio pensamento e modo de compreensão" (p. 33).

O que traremos em seguida é o resultado da análise existencial que empreendemos, organizada da seguinte forma: apresentaremos o resumo do conteúdo presente no discurso de cada um dos sete analisandos que foram objeto de nossa investigação. Após cada descrição ou resumo, traremos os sentidos que retiramos em relação aos dois temas que nos interessam aqui: desespero e sofrimento. A título de conclusão da pesquisa, buscaremos resumir as impressões que ficaram das análises realizadas. 


\section{Análise existencial das situações clínicas}

\subsection{Prefiro morrer}

Sexo Feminino, 27 anos.

A analisanda viveu uma crise e resolveu parar tudo, estudos, trabalho. Tentou se matar. O dinheiro acabou e agora voltou a viver na casa dos pais. Queixa-se constantemente por não poder fazer as coisas do jeito que gosta. Rejeita os limites impostos pela mãe, pelos horários da faculdade e pelos da terapia: faz barganhas, mente, tenta manipular para não se submeter. Quando o limite não pode ser transposto revoltase, quer morrer. Numa situação em que sofreu um assalto, reagiu impulsivamente e fugiu. Depois do ocorrido, deu-se conta que poderia ter levado um tiro. A vulnerabilidade se fez presente a partir desta situação, o que ela não consegue suportar. Agora só faz dormir, pois sente muito cansaço. Não vê sentido em nada. O ânimo só aparece quando fala dos animaizinhos que pegou para criar e vender. Tem um namorado e se distrai com a filha dele. Quando está na casa dele e a filha não está, também só dorme.

Percebemos que, diante da impossibilidade de impor sua medida, a desesperança ganha volume na existência desta analisanda. Ela oscila: ora quer morrer, ora tranca-se em si mesma. A vontade se minimiza, não crê em si mesma, nenhuma possibilidade parece realmente possível para si. Assume aquela posição que Anticlimacus (KIERKEGAARD, 2010b) descreve como desespero da sua fraqueza. Ela ignora que deve tornar-se si mesma e, nesse ignorar, só conhece o instante, o agora, o qual se arrasta como uma sequência de nada. Morrer aparece como uma saída, embora não saiba por que morrer, pois viver e morrer estão esvaziados de sentido. Por isso, a vida da analisanda oscila entre ser espontânea, distraindo-se com alguns empreendimentos, revoltar-se ou fechar-se em si mesma.

Essa analisanda se lamenta frequentemente sobre as condições adversas de sua vida, queixa-se por ter crises que a fazem interromper seus projetos. Essas atitudes correspondem, conforme as contribuições filosóficas explicitadas anteriormente, ao sofrimento, à dor da dor. Ela reclama por sentir a dor do peso do mundo, das exigências feitas a ela, tais como: preparar seus objetos para sua mudança, fazer vendas, doações, etc. Recorrentemente, em situações que a desagradam ou apresentam um desagrado em potencial, prefere se ausentar para evitar a tensão. Sente-se tensa a todo o momento, menos quando toma seus remédios para dormir. O suicídio aparece para ela, em suas 
palavras, como "uma saída para os sentimentos chatos, a vida que está uma merda" (sic). Em outro momento, referindo-se ao assalto, afirma: "para quê estou tentando viver, para passar por esse tipo de situação?" (sic).

Cabe-nos refletir sobre o que faz com que o suicídio apareça como saída para a dor. Um caminho possível é aquele apontado por Feijoo (2017) de que, na contemporaneidade, a dor tende a ser vista como algo a ser extirpado. Assim, tanto naquele que pensa em suicídio, como naquele em que essa ideia nunca foi ventilada, escapar da dor, por todos os meios que nos são dados, aparece. Nesse sentido, prolifera a pergunta, em ambos os casos, que caracteriza o sofrimento: "por que aconteceu isso comigo?", tendo-se em conta que o mundo nos diz que vida pode não comportar dor. Logo, a medicalização da vida, as terapias, e até mesmo o suicídio podem configurar tentativas de suprimir a dor ou o sofrimento tal como veiculado em nosso tempo.

\subsection{Tenho medo e vergonha}

Sexo Feminino, 21 anos.

A analisanda descreve situações de medo e de vergonha por sentir tanto medo. Teme a possibilidade de fracassar, as críticas dos amigos e da família, como também teme decepcionar as pessoas, especialmente a madrinha. Sente medo de não ser amada como filha, de não saber decidir-se sobre o que quer fazer ou sobre onde viver: se com o pai ou com a madrinha, situações que lhe são requisitadas e às quais adia responder. $\mathrm{O}$ pensamento de morte lhe vem sempre que lhe dizem algo desagradável sobre sua identidade e ela tem vergonha de falar sobre isso com as pessoas. Pensa que morrendo acabará esse peso que ela carrega, bem como a culpa e o medo.

A indecisão se mostra como a tônica na vida desta analisanda, que ignora a si mesma como desespero, ou seja, como tendo de ser essa que só ela pode ser. Ela oscila entre as categorias do agradável e do desagradável e desconhece sua "finalidade espiritual" (KIERKEGAARD, 2010 b, p. 61), na medida em que se recusa a arriscar-se e a entregar-se às possibilidades que se abrem para ela. Ao desconhecer sua situação de já estar dando uma direção para sua existência, a direção da evitação, a analisanda ilude-se pensando que não está em risco. Ela não percebe que está, justamente, no maior dos riscos, o de perder a si mesma tornando-se um nada, um zero. Kierkegaard (2010b) diz que tornar-se um zero é ser mais um na multidão, uma repetição do mesmo. Sem coragem 
de arriscar e de deixar-se educar ou se fortalecer nas circunstâncias que são as suas, ela escolhe ser igual aos outros, uma imitação, uma autômata.

Vemos, nessa situação, o sofrimento motivando o pôr fim à vida. As circunstâncias da vida dessa analisanda são, para ela, motivos de lástima. Ela pensa em dar fim à sua vida, por ser muito sofrido viver com a ameaça do fracasso e com incertezas com relação às pessoas próximas. Nesse caso, notamos o lidar com situações tensas ao modo da evitação, como se fosse possível evitar a tensão. Mais uma vez, há indícios de que é a crença presente em nosso horizonte histórico de que é possível viver sem dor que motiva esse modo de lida com a dor.

\subsection{Não quero mais ouvir calada}

Sexo feminino, 36 anos.

A analisanda relata conflitos com a mãe, que descreve como uma pessoa que só a procura apresentando problemas. Ela ressente-se da falta de apoio da mãe quando ela era jovem e narra que resolveu sair de casa e ir morar com a madrinha, diz que recentemente resolveu não mais ouvir as coisas e ficar calada. Está fazendo assim com a mãe e também no trabalho, denunciando limites para as situações e ressentindo-se por seu modo ético de agir não ser reconhecido por sua chefia. Narra que, ao tentar atender a tantas demandas, estava carregando um saco de cinco quilos nas costas e chegou a pensar que não tinha mais por que viver. Só servia para ouvir ou dar problemas. Resolveu mudar, colocar um fim nisto, pois pensou que Deus deu a vida para cada um carregar a sua.

A analisanda assume o risco de errar, de se perder, porque quer se encontrar, quer ficar bem consigo mesma. Nessa luta, ela experimenta saídas, outros modos de agir. Kierkegaard (2010b) poderia dizer que ela lida com sua situação ao modo do desafio. "Ela não se submete. Na luta por tornar-se o que pode ser, acredita em sua superioridade infinita sobre as outras pessoas" (p. 95). Seu agir, no entanto, não encontra constância. Assim ela oscila entre a força por não se deixar abater, por experimentar outros caminhos, e o desejo de morte. O desejo de morrer parece ser o desejo de se livrar de tanta luta e tanta miséria. O que a vida lhe exige é medido como demais, além da conta e, nisso, consiste seu desesperar-se.

Essa analisanda relata sobre seu sofrimento, o qual apresenta intermitências. Às vezes sente conforto ao saber que faz as coisas de acordo com suas referências pessoais; noutras, reclama porque age corretamente e não tem o retorno esperado. Parece haver 
ocorrido, no decorrer da psicoterapia, uma transformação: as lamentações deram lugar, em grande parte, aos relatos sobre mudanças de posicionamentos e atitudes. Por isso, arriscamo-nos a dizer que há, agora, em sua existência, uma maior aceitação do caráter trágico, ainda que essa característica mais recente se veja balançada em certas ocasiões. Ressaltamos que a psicoterapia que conduzimos não tem pretensões de extirpar a dor e, sim, de deixar aparecer que vida também comporta dor.

\subsection{Diga-me o que fazer}

Sexo masculino, cerca de 30 anos.

$\mathrm{O}$ analisando relata que brigou com seus colegas de trabalho. O motivo da desavença foi o seu modo de proceder com relação ao patrão, fazendo críticas, dando palpite de como esse último deveria organizar o negócio. $\mathrm{O}$ analisando afirma que devia ter mais paciência, que sabe ter sido explosivo, mas ficou com muita raiva. Em seguida, quer receber da terapeuta a orientação de como deve agir. Ele relata tomar medicamento para se controlar, ficando muito agitado quando não o faz. Essa agitação é considerada por ele como uma qualidade para o seu trabalho, mas também como uma característica muito estressante. Seu problema, conforme disse, consiste em não saber ser de outro modo. Por isso, ele requisita diretrizes de ação da terapeuta e pensa que essa tarefa cabe a ela.

Aqui, assim como na situação descrita acima, encontramos um modo desafiador de ser. O rapaz entende a situação em que está e na qual age de forma impaciente diante do que não aprova. Ele critica o outro porque quer que tudo funcione ao modo como concebe. Embora saiba que se comporta de modo impulsivo, identifica as vantagens de agir deste modo no trabalho, pois se torna mais ágil. Mas também fica agressivo, quer impor as condições a qualquer preço. Oscila entre controlar-se e perder o controle. Quer uma saída rápida e cobra conselhos da terapeuta, como se lhe fosse possível seguir conselhos. Vivendo no imediato, ele só conhece suas disposições e o modo como, subitamente, impulsivamente, corresponde de um jeito ou de outro aos apelos do mundo. Na tensão com o tempo, ele ignora o caráter de duração de sua existência. Não conhece o amanhã, o depois. Conhece apenas o momento presente, ao qual se entrega irrefletidamente. Depois, desespera-se porque as coisas não se deram como queria.

$\mathrm{O}$ analisando sofre, sobretudo, porque as coisas não podem funcionar a partir de sua lógica. Em seu sofrimento, quer que lhe digam o que fazer, que lhe ajudem a não agir 
de forma impulsiva e a aprender a esperar. Ele almeja conquistar constância em seu modo de existir, agindo de maneira impaciente, sem a meditação sobre as circunstâncias de sua vida. Podemos dizer que a impaciência é uma característica marcante do nosso tempo, no qual todos, sejam aqueles que pensam em suicídio ou não, tendem a possuir ritmo apressado e irrefletido (HAN, 2016). Na impaciência, tende-se a perder a oportunidade de reflexão, dificultando-se a aparição de outros modos possíveis de ser.

\subsection{Só tenho do que me arrepender}

Sexo feminino, 25 anos.

A analisanda nasceu de uma relação extraconjugal e relata que o pai não a registrou, mas ficou próximo dela por um tempo. Depois, distanciou-se. Isso fez com que ela pensasse em suicidar-se. Ele a colocou numa escola particular, onde sofria com o bullying e com as diferenças dessa instituição em relação à sua escola anterior. Acionou um processo judicial contra o pai, para receber sua pensão. Ele ora paga, ora não paga. Ela diz que às vezes surta e que precisa de acolhimento. Certa vez, tentou impedir uma briga da mãe com o pai e teve uma crise depressiva - normalmente toma muitos remédios e se corta nesse tipo de crise, preferindo dormir ou fugir, porque a mãe sempre aumenta as coisas. Ela declara não ter mais ânimo para fazer nada.

No seu trabalho também todos estão tristes e desanimados, pois estão sem receber salário. Ela se sente sobrecarregada ao procurarem-na para conversar sobre essa situação. Por consequência disso, diz não estar aguentando mais e preferir largar o emprego. Lamenta-se, também, porque não tem mais o corpo que tinha aos 18 anos e se arrepende por ter abandonado a faculdade. Aliás, reitera só ter do que se arrepender em sua vida, pois nada de bom lhe acontece e, por isso, pensa que não vale a pena viver. Esse pensamento a domina quando está em crise. Em consulta com um neurologista, este lhe indicou dois caminhos: esquecer o passado ou suicidar-se. Ela fala que há muito que ela podia e queria e, no entanto, não faz. Seu desejo é o de que os acontecimentos fossem de outro modo. Identifica complicações ao procurar emprego e não gosta de tomar decisões, principalmente se são importantes.

A analisanda queixa-se quanto às condições que lhe foram impostas pela vida, ressentindo-se quanto ao modo como as coisas se deram. Sente-se desanimada, arrependida pelos caminhos percorridos ou não percorridos, referindo-se a dificuldades em tomar decisões. O tempo verbal adotado no discurso evidencia o espaço da 
imaginação. De acordo com isto, o querer mostra seu limite ao não se efetivar em ação. É claro que a situação concreta não está fácil. A crise no trabalho, o não estar recebendo salário foge, completamente, do seu campo de possibilidades. A tristeza, conforme relata, é tônica no ambiente compartilhado com os colegas. Nessa crise a vida lhe é devolvida, e ela se arrepende dos caminhos não trilhados, do corpo que não tem mais. E se lamenta por não aguentar mais tanta queixa dos colegas. Segundo Haufniensis (KIERKEGAARD, 2010a), este é o campo propício para a aprendizagem da possibilidade. Neste espaço ela pode aprender acerca do que quer para si mesma e do que pode, arriscando novos possíveis. Se não tivesse tanto medo de arrepender-se, se não se desesperasse por sua condição.

Como vimos anteriormente nas considerações filosóficas, o caráter trágico da vida não implica necessariamente em sofrimento. No entanto, esse encadeamento comumente sucede no caso dessa analisanda. Acontecimentos como a crise no trabalho, a mudança de seu corpo, largar a faculdade a fazem lamentar, sofrer. Essa é uma possibilidade que aparece singularmente, mas que evidencia uma característica de nosso horizonte histórico, no qual as situações de dor tendem a ser tomadas como algo a ser eliminado. Diante da impossibilidade de erradicação da dor, habitualmente ocorre o aborrecimento, o desgosto, o sofrimento. Lembramos, novamente, que se trata de uma questão recorrente tanto naqueles que pensam em suicídio como nos que não pensam.

\subsection{Quero ser levado a sério}

Sexo masculino, 39 anos.

$\mathrm{O}$ analisando relata que quis retornar à psicoterapia depois da quarta tentativa de suicídio. Ele diz: "as pessoas não me levam a sério por causa do meu transtorno [bipolar] diagnosticado aos 22 anos" (sic). Conta que ficou mal desde a morte do pai, aos 15 anos. Fez planos de, aos 33 anos, dar uma festa e um tiro na cabeça na frente de todo mundo. A última tentativa de se matar aconteceu após briga com a namorada. Enfileirou uns comprimidos e enviou a foto para uns amigos. Disse que queria provar se havia mesmo livre arbítrio. Se morresse, confirmaria a existência do livre arbítrio. Conclui, entretanto, não haver livre arbítrio, pois "um deus ou algo superior não me deixou morrer" (sic).

Na relação com seus familiares, ele relata que sua mãe e seu irmão são seus piores inimigos, os quais cobram dele a conclusão da faculdade, o fixar-se num emprego e o alcançar a independência. Jogam na cara dele que ele não é nada. Expõe, também, que a 
briga com a namorada aconteceu por causa de uma dívida que ele contraiu. A namorada duvidou que ele pagaria a dívida, o que o deixou com muita raiva. Ele conta que se endividou todo, pagou a dívida e ela sumiu. Brigou com ela, foi violento. Agora está sofrendo muito por causa dela.

O analisando percebe que há momentos em que está interessado nas coisas, depois perde o interesse, como aconteceu quando abandonou a faculdade: "não sei o que acontece que perco o interesse" (sic). Na tentativa de ganhar dinheiro, alugou um carro e começou a trabalhar de Uber, o que está fazendo há uma semana. Ele conta à psicoterapeuta seus planos para pagar as dívidas assumidas, sair de casa e morar só. Também planeja fazer uma grande festa de 40 anos. Na semana seguinte sofre um acidente com o carro e agora terá que pagar o conserto do carro, além da dívida que já tinha. Mas imagina que tudo dará certo, se inscreveu num curso e vai conseguir trabalhar e pagar tudo em dezembro.

O que percebemos é que na relação entre a finitude da realidade e a infinitude das possibilidades, o analisando se atém ao imaginário, de modo que a realidade não tem força suficiente para valer como guia de sua relação com a vida. Embora ele relate sua própria oscilação entre interesse e desinteresse, esta experiência é insuficiente para fixalo à realidade, perdendo-se nos possíveis de sua imaginação. É o que Anticlimacus (KIERKEGAARD, 2010b) descreve como desespero do infinito por carência de finitude. Ele desconhece seus limites, acredita poder o que não pode. Vive apenas o presente, que experimenta com força tal que parece que durará até o futuro. Não percebe que essa elasticidade está no imaginário, carecendo de ações reais que promoveriam sua realização. Ignora sua situação de desespero, ou seja, de que deve tornar-se si mesmo.

Ele sofre porque os outros não acreditam nele, provavelmente por conta de suas atitudes impulsivas, irrefletidas. A revolta com o fato de as pessoas não o levarem a sério é o seu sofrimento. Esse traço marca suas tentativas ou planejamentos de suicídio, os quais parecem ser um meio de mostrar o que ele pode fazer e que deverá ser levado a sério. Parece ser difícil para ele perceber os motivos da descrença por parte dos outros, pois ele mesmo relata não saber ao certo o que acontece. Acreditamos que a psicoterapia pode facilitar a apropriação deste analisando à sua condição existencial, o que pode resultar em modos menos sofridos de lida com a dor. 


\subsection{Só o suicídio me tiraria dessa situação}

Sexo feminino, 20 anos.

A analisanda relata que se cortava, envergonhando-se por isto. Pensava em morrer. Ressente-se por não estar bem, ela diz ter altos e baixos. Conta à terapeuta que se sente mal em casa, pois a irmã a chama de inútil. Foi morar com o pai e o mesmo aconteceu na casa dele, ele também a chamava de inútil. Menciona que confia nas pessoas e depois é traída. Logo, passou a desconfiar de todo mundo. A mãe morreu em 2015 e, segundo conta a analisanda, ela foi a única pessoa da família que sofreu. Conclui que o pai e a irmã não viveram o luto pela perda da mãe e que ela não podia vivê-lo, não podia sofrer. Só conversava com o namorado, o qual era abusivo, e isso mudou seu modo de relacionar-se com as pessoas, a afastando dos outros. A mãe era uma referência para ela. Refere-se à dificuldade em interagir com as pessoas, de conseguir emprego. Teme ser julgada, e pensa que com o suicídio ficaria livre do julgamento, seria um modo rápido de resolver.

A analisanda está desesperada. Ela experimenta o que Anticlimacus (KIERKEGAARD, 2010b) descreve como desespero fraqueza: nenhum possível parece realmente possível e morrer aparece como uma saída para sua situação. Na tensão com o tempo, sua vida parece ter parado na circunstância da morte da mãe. Na tensão com as circunstâncias de sua existência, a analisanda se fixa ao necessário e esquece-se dos possíveis. Num horizonte que exige pressa e realizações, em que não se pode parar, a analisanda não encontra espaço para experimentar sua dor, fortalecer-se e, quem sabe, voltar a enxergar possíveis na realidade. O suicídio ou a medicalização resolveriam sua situação, acabariam com a tensão. O fato de estar em psicoterapia, falando de sua situação, sustenta esse espaço de demora no qual os possíveis podem aparecer.

O sentimento de incompreensão indica o motivo do sofrimento da analisanda. É difícil para ela compartilhar sua situação com os outros, mas gostaria de ser compreendida. Ela comenta sobre o que a aflige a um amigo, e isso a alivia. Entretanto, a reação do amigo a desagrada e ela se dá conta durante a consulta de que ficou magoada, mas não teve coragem de contar a ele. O suicídio aparece-lhe como uma solução para a dificuldade de interação com as pessoas e de conseguir um emprego. O diálogo consigo mesma parece difícil, ela se embaraça ao tentar se compreender. Talvez, no decorrer da psicoterapia, essa compreensão seja facilitada e ela possa vislumbrar outras formas de lidar com sua dor. 


\section{Compreensões que articulamos sobre o fenômeno suicídio}

O desespero, compreendido cotidianamente, parece referir-se a um sofrimento ou, como diz Fogel (2010), a uma dor da dor. Tal posicionamento sustenta-se na ilusão de que há vida sem dor e sem tarefa. Compreendemos com Kierkegaard, fala da situação do homem, de sua tarefa de ter de tornar-se o único que somente ele pode ser, seja ele alguém que pensa em se matar ou não. Não há como sermos substituídos na tarefa de vivermos a vida que é nossa. Mas, como pudemos ver nos discursos descritos acima, tendemos a nos desesperar, ou seja, a tentar terceirizar essa tarefa, assim como a culpabilizar terceiros pela dificuldade da tarefa. Uma charge argentina de Quino, diz: "Por qué justo a mí tenía que tocarme ser yo?" (LAVADO, s.d.). Ou, em uma versão em português: Por que justo a mim me coube ser eu? Essa charge nos mostra claramente como a tarefa de conduzir a vida é algo que aparece com muita ênfase em nosso momento histórico.

Nas análises realizadas acima, tentamos evidenciar os modos diferentes de articulação com a existência, ou seja, diferentes modos de sermos na tensão entre as facticidades de nossa vida. Procuramos destacar que, em cada caso, o que está em questão é a forma como, dentre as condições dadas, se desenham os modos de articulação. E, mais, como, em cada articulação, a impaciência aparece no modo como se tenta impor a vontade sobre as circunstâncias ou se vive no ressentimento porque as circunstâncias não atendem às expectativas. Na impaciência o tempo do acontecimento, com suas caracterizações próprias, é apressado, como se fosse possível impor à vida o como e o quando ela deve ser como se quer. E o que se perde é o caráter singular da vida, ou seja, que o tempo é o tempo de cada articulação com as coisas da vida e consigo mesmo. Vida não é uma abstração, mas a minha vida.

Com relação à articulação entre desespero e suicídio, pudemos perceber que o desejo de morrer nem sempre aparece em termos do que expomos acerca de desespero, ou seja, na qual o analisando estaria consciente de que sua vida, nas suas condições próprias, é a vida com a qual precisa se articular. Isso ficou claro nos discursos em que alguns analisandos responsabilizavam amigos ou familiares por sua situação, acreditando que o mundo é que precisa mudar para que eles continuem a viver, ignorando a si mesmos como agentes na situação. Neste caso, a ilusão é acreditar que sua ação é necessidade, e não possibilidade. É o que compreendemos como estar desesperado.

Acerca de dor e sofrimento, podemos apontar alguns elementos que se repetiram com mais frequência e nos chamaram a atenção nos discursos clínicos. Um deles é queixa 
sobre a incompreensão dos outros. Muitos analisandos gostariam de ser compreendidos de maneira diversa à que efetivamente se dá, o que se torna motivo de sofrimento. $\mathrm{O}$ fato de doenças, tentativas de suicídio, variações de humor, ações, desejos, etc. não serem compreendidos por outras pessoas da forma esperada enseja, por vezes, o pensar em suicídio, dentre outros.

Outro elemento percebido em alguns relatos é a lida com a dor ao modo do não suportar, da "evitação". Há analisandos que tratam de esquivar-se de situações doídas, pois não as toleram. Frequentemente, na literatura científica e no senso comum, considera-se uma inabilidade na lida com experiências de dor o fato de se cogitar ou tentar suicídio em virtude das mesmas. Pensamos não nos caber a tarefa de dizer como deve ser a lida com a dor, ou de afirmar que evita-la consiste em uma forma defectiva de se tratar dela. Neste texto, por não reputarmos juízos de valor a esse jeito de abordar a dor, consideramos que tratar de evita-la é apenas um modo de ocupar-se da mesma, ainda que de maneira evasiva.

Ressaltamos, ademais, o tema do sofrimento por viver sem sentido, apontado por diversos analisandos. Parece-nos haver uma expectativa de que a vida tenha um sentido transcendente que a fundamente, ou um objetivo contundente que ajude a suportar as dores. Alguns analisandos, ao se depararem com a falta de sentido, por vezes sofrem e pensam em suicídio. Destacamos, ainda, o fato de o desemprego e de dificuldades econômicas serem reiteradamente motivo de sofrimento e de pensar em suicídio. Um outro elemento que apontamos aqui, não com a intenção de estabelecer categorias identificatórias, mas sim de evidenciar possibilidades de lida com a dor da vida, é a automutilação. Fazer cortes no próprio corpo, ainda que nem sempre tenha a ver com suicídio, foi-nos relatado como uma prática que alivia uma dor dita psicológica ou emocional.

Com relação ao fazer clínico, consideramos que nossa investigação mostrou que ao nos debruçarmos sobre o modo de articulação em cada situação, nos demorarmos nelas pacientemente, apareceram outras possibilidades de compreensão no que se refere a desespero, dor e sofrimento, tanto para analista quanto para analisando. Essas possibilidades se mostraram como caminhos a serem traçados no diálogo participativo, caminhos que podiam sustentar o que realmente estava em questão quando cada um agia como agia. Acreditamos que, no demorar-se junto aos analisandos, outros modos de articulação e de ação podem mostrarem-se. Sabemos não se tratar nunca de um problema que requer solução, mas de esclarecimentos sobre aquele modo específico de articulação 
existencial, ou seja, da minha vida. O pronome possessivo não se refere a uma articulação particular, mas ao modo como vida não acontece de forma abstrata, mas sempre como articulações singulares, com nome e sobrenome. Assim, concluímos que as questões que aparecem naqueles que pensam em suicídio são as mesmas que se fazem presentes nos que não pensam em tirar a própria vida. Trata-se apenas de decisão quanto ao caminho a tomar frente à dor, ao sofrimento e ao desespero. O objetivo da relação psicoterapêutica, em ambos os casos, não é um conhecimento sobre a pessoa ou sobre a situação em questão, mas, principalmente, uma realização, uma arte, que cria e recria possibilidades onde parece só haver restrições e necessidade.

\section{Considerações finais}

Apesar de todos os analisandos que foram encaminhados ou chegaram ao NAC trazerem a questão da indecisão por tirar a própria vida, observamos como esse tema tomava várias roupagens nos discursos clínicos, ora como queixa, como ressentimento, como desejo de mudança, desesperança, etc. Aconteceu, inclusive, de a temática do suicídio não ser mais retomada após o encaminhamento ou primeira sessão. Ainda que o pensamento acerca de se matar não estivesse evidente nos discursos, era possível identificar, por vezes, sofrimento e modalidades de desespero como elementos que se destacavam. O contrário também acontecia, ou seja, o discurso trazia a indecisão por tirar a própria vida sem dar destaque ao sofrimento ou desespero.

Entendemos, analisando grande parte dos relatos clínicos, que o sofrimento não veio acompanhado da exposição da intenção de pôr fim à própria vida. Em outros momentos, a temática do suicídio evidenciou-se sem que se identificasse a presença de sofrimento. Em outras ocasiões, mostrou-se o sofrimento relacionado à intenção de suicídio. Isso evidencia a importância de conservarmos a escuta atenta, não antepondo às falas dos analisandos aquilo que não se fez evidente, ou seja, não pressupondo que sofrimento e suicídio estão sempre relacionados.

A análise que empreendemos mostrou o modo como os discursos universais ou gerais encurtam a compreensão do fenômeno do suicídio, não deixando que apareçam as especificidades vigentes em cada situação. Também pudemos ver como há uma tendência geral a este encobrimento, na tentativa apressada de sair da dor, de extrair de si qualquer sofrimento, negando-se a encarar a existência em seu caráter trágico, ou seja, de desespero. Em nossa investigação buscamos acender uma luz sobre estas questões, de 
forma a nos libertarmos para seguirmos outros caminhos de pensamento quando tentamos entender a relação entre desespero, sofrimento e suicídio.

Para finalizar, ressaltamos que a dor, sofrimento e desespero bem como as suas diferentes expressões não caracterizam e nem identificam o potencial suicida, portanto, não devem ser utilizados como identificadores nem definidores de um perfil.

\section{Referências}

FEIJOO, A. M. L. C. D. Por Um Núcleo de Atendimento Clínico a Pessoas em Risco de Suicídio, Rio de Janeiro, 2016. Disponivel em: <http://www.ifen.com.br/site/producoesacademicas/projetos/197-projeto-de-pesquisa-bolsa-produtividade-cnpq>. Acesso em: 21 jan. 2018.

FEIJOO, A. M. L. C. D. Dor, Sofrimento E Desespero: Do Homem Grego Ao Homem Moderno. In: FEIJOO, A. M. L. C. D. (Org.) Interpretações Fenomenológico-Existenciais Para O Sofrimento Psíquico Na Atualidade. 2. ed. Rio de Janeiro: IFEN, 2017b. p. 7-30.

FEIJOO, A. M. L. C. D. (Org.) Suicídio entre o morrer e o viver: desmoralizando o suicídio na contemporaneidade. Rio de Janeiro: IFEN, 2018.

FEIJOO, A. M. L. C. D.; PROTASIO, M. M. Análise existencial: uma psicologia de inspiração kierkegaardiana. Arquivos brasileiros de psicologia, Rio de Janeiro, 63, n. 3, 2011. 72-88. Disponivel em: <http://pepsic.bvsalud.org/scielo.php?script=sci_arttext\&pid=S180952672011000400007\&lng=pt\&nrm=iso >. Acesso em: 26 Janeiro 2018.

FERRO, N. Naturalmente hipócrita: Linguagem e desonestidade no pensamento de Kierkegaard. In: VALLS, A. L. M.; FERREIRA, G. Compêndio Kierkegaard. 1. ed. São Paulo: LiberArs, 2015. p. 61- 89.

FOGEL, G. O Homem Doente do Homem e a Transfiguração da Dor: Uma Leitura de Da visão e do enigma em Assim falava Zaratustra, de Frederico Nietzche. 2. ed. Rio de Janeiro: Mauad, 2010.

HAN, B. C. Sociedade do Cansaço. 2. ed. Petrópolis: Vozes, 2016.

KIERKEGAARD, S. A. Ancient's Tragedy Reflection In The Modern. In: KIERKEGAARD, S. A. Either/Or. Tradução de A. Hannay. 1. ed. Londres: Penguin, 1992. p. 134-159.

KIERKEGAARD, S. A. O conceito de angústia. Tradução de Álvaro Luiz Montenegro Valls.

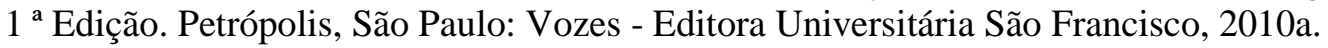

KIERKEGAARD, S. A. O desespero humano. Tradução de Adolfo Casais Monteiro. $1^{\text {a }}$ Edição. São Paulo: Editora Unesp, 2010 b.

LAVADO, J. S. Mafalda. Wikiquote. Disponivel em: 〈https://es.wikiquote.org/wiki/Mafalda〉. Acesso em: 27 jan. 2018.

MAGLIANO, F. D. R. Considerações preliminares sobre a compreensão e finitude humana. In: FEIJOO, A. M. L. C. D. (Org.) Suicídio entre o morrer e o viver: desmoralizando o suicídio na contemporaneidade. 1. ed. Rio de Janeiro: IFEN, 2018. p. 17-37. 
PROTASIO, M. M. Camus e Kierkegaard: do absurdo ao desespero. In: FEIJOO, A. M. L. C. D. (Org.) Suicídio entre o morrer e o viver: desmoralizando o suicídio na contemporaneidade. 1. ed. Rio de Janeiro: IFEN, 2018. p. 231-265.

SANT'ANNA, G. D. S. Dor, sofrimento e pôr fim à vida: uma análise crítica. In: FEIJOO, A. M. L. C. D. (Org.) Suicídio entre o morrer e o viver: desmoralizando o suicídio na contemporaneidade. Rio de Janeiro: IFEN, 2018. p. 171-194.

SANTOS, D. V. D. D. Suicídio: De quem é o problema? Conselho Regional de Psicologia SP, setembro-outubro 2011. Disponivel em:

<http://www.crpsp.org.br/portal/comunicacao/jornal_crp/170/frames/fr_conversando.aspx> . Acesso em: 27 jan. 2018.

XAVIER, I. F. L. A (in)decisão de pôr fim à vida: uma análise fenomenológica dos discursos clínicos. In: FEIJOO, A. M. L. C. D. Suicídio entre o morrer e o viver: desmoralizando o suicídio na contemporaneidade. 1. ed. Rio de Janeiro: IFEN, 2018. p. 267-291.

Recebido em: 12 de fevereiro de 2018.

Aceito em: 02 de julho 2018. 